\title{
Vitamin K4 inhibits the proliferation and induces apoptosis of U2OS osteosarcoma cells via mitochondrial dysfunction
}

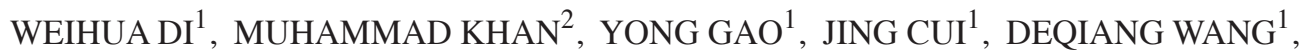 \\ MINGFEN QU ${ }^{1}$, LIANGTAO FENG ${ }^{1}$, AMARA MARYAM ${ }^{2}$ and HONGWEN GAO ${ }^{3}$ \\ ${ }^{1}$ Department of Pain Treatment, Binzhou Medical University Affiliated Hospital, Binzhou, Shandong 256600; \\ ${ }^{2}$ College of Basic Medical Sciences, Dalian Medical University, Dalian, Liaoning 116041; \\ ${ }^{3}$ Department of Pathology, Jilin University Bethune Second Hospital, Changchun, Jilin 130041, P.R. China
}

Received October 11, 2015; Accepted September 2, 2016

DOI: $10.3892 / \mathrm{mmr} .2016 .6001$

\begin{abstract}
Vitamin K (VK) is a group of fat-soluble vitamins, which serve important roles in blood coagulation and bone metabolism. A recent study reported that several VK subtypes possess antitumor properties, however the antitumor effects of VK in osteosarcoma are unknown. The present study aimed to identify the antitumor effects of VK in osteosarcoma and the possible underlying mechanism of action. The effect of VK4 on cell viability was determined using a 3-(4,5-dimethylthiazol-2-yl)-2,5-diphenyltetrazolium bromide (MTT) assay. Cellular and nuclear morphological changes were observed by phase contrast microscopy. Cell cycle analysis, apoptotic rate, mitochondrial membrane potential and levels of reactive oxygen species (ROS) were detected by flow cytometry. In vitro cancer cell migration activities were evaluated using a Wound healing assay and Transwell microplates. The results demonstrated that VK4 arrested the cells in S phase and induced apoptosis. Additional mechanistic studies indicated that the induction of apoptosis by VK4 was associated with the increased production of reactive oxygen species, dissipation of the mitochondrial membrane potential, decreased Bcl-2 family protein expression levels and activation of caspase-3. In conclusion, the results suggest that the sensitivity of U2OS osteosarcoma cells to VK4 may be as a result of mitochondrial dysfunction. As it is readily available for human consumption, VK4 may therefore present a novel therapeutic candidate for the treatment of patients with osteosarcoma.
\end{abstract}

Correspondence to: Professor Hongwen Gao, Department of Pathology, Jilin University Bethune Second Hospital, 218 Ziqiang Street, Changchun, Jilin 130041, P.R. China

E-mail: gaohongwen@jlu.edu.cn

Key words: vitamin $\mathrm{K} 4$, osteosarcoma, Bcl-2 family proteins, caspase-3

\section{Introduction}

Osteosarcoma is the most common bone malignancy diagnosed in children and young adults (1-3), and the overall five-year survival rate of patients with osteosarcoma is $\sim 61.6 \%$ (1). Prior to the 1970 's, when the standard treatment primarily consisted of surgical resection, the prognosis of patients with osteosarcoma was poor, with five-year survival rates of $<20 \%(2,4)$. Over the last few decades, the combined use of multi-agent chemotherapy and surgery has improved the five-year survival rates of patients with osteosarcoma to $60-70 \%(1,4)$. Although the use of effective adjuvant chemotherapeutic agents has improved the survival rates dramatically, the prognosis for patients with osteosarcoma remains unsatisfactory $(5,6)$. Therefore, the identification of novel chemotherapeutic agents, and the molecular mechanisms by which they function, are important for improving the outcome of osteosarcoma treatment.

Vitamin $\mathrm{K}(\mathrm{VK})$ is a group of fat-soluble vitamins that serve important roles in blood coagulation and bone metabolism (7). VK exist as natural and synthetic forms. VK1 (phylloquinone) and VK2 (menaquinone) are naturally occurring vitamins, which are produced by plants and bacteria, respectively (7-14). VK3 and VK4 (menadiones) are synthetic derivatives of VK1 and VK2 (14). In recent years, an increasing number of studies have investigated the antitumor effects of VKs (7-14). These studies have demonstrated that VK inhibits the growth and induces apoptosis in multiple cancer cell types, including leukemia, hepatocellular carcinoma, and lung, breast, oral, bladder and prostate cancers (7-14). The anticancer activity of VK4 in prostate cancer cells was demonstrated by Jiang et al (14). However, the molecular mechanisms underlying VK4-induced apoptosis in these cells remain largely unknown. Therefore, the aim of the present study was to investigate whether VK4 exerts anticancer effects in osteosarcoma cells, and to identify the potential molecular mechanisms involved.

\section{Materials and methods}

Chemicals and antibodies. All chemicals were purchased from Sigma-Aldrich (Merck Millipore, Darmstadt, Germany) 
unless otherwise stated. VK4 was purchased from Shanghai Tauto Biotech Co., Ltd. (Shanghai, China), and the chemical structure of VK4 is shown in Fig. 1A. Fetal bovine serum (FBS) was purchased from Hangzhou Sijiqing Biological Engineering Materials Co., Ltd. (Hangzhou, China). The Annexin V-FITC Apoptosis Detection kit, Reactive Oxygen Species assay kit and primary antibodies against Bax, Bcl-2 and caspase-3 were purchased from Beyotime Institute of Biotechnology (Shanghai, China). The $\beta$-actin primary antibody and the horseradish peroxidase (HRP)-conjugated goat anti-rabbit IgG or goat anti-mouse IgG secondary antibodies were purchased from Santa Cruz Biotechnology, Inc. (Dallas, TX, USA).

Cell culture and treatments. The human osteosarcoma U2OS cell line was obtained from the American Type Culture Collection (Manassas, VA, USA) and cultured in Dulbecco's Modified Eagle's Medium (DMEM) supplemented with $10 \%$ FBS, $100 \mathrm{U} / \mathrm{ml}$ penicillin and $100 \mu \mathrm{g} / \mathrm{ml}$ streptomycin at $37^{\circ} \mathrm{C}$ and $5 \% \mathrm{CO}_{2}$ in a humidified atmosphere. VK4 was dissolved in dimethyl sulfoxide (DMSO). Cells were treated with 0,25 or $35 \mu \mathrm{M}$ VK4 dissolved in DMSO, where the final concentration of DMSO was $<1 \%$. DMSO-only treated cells were used as a control.

Determination of cell viability. The effect of VK4 on cell viability was determined using the 3-(4,5-dimethylthiazol-2-yl)-2,5-diphenyltetrazolium bromide (MTT; Sigma-Aldrich; Merck Millipore, Darmstadt, Germany) assay as described previously (9). Briefly, $1 \times 10^{4}$ U2OS cells/well were seeded in a 96-well plate and treated with $0,5,10,12.5$, $20,25,35,40$, and $100 \mu \mathrm{M}$ VK4 for $24 \mathrm{~h}$. Following treatment, MTT reagent $(500 \mu \mathrm{g} / \mathrm{ml})$ was added and cells were incubated at $37^{\circ} \mathrm{C}$ for a further $4 \mathrm{~h}$. DMSO $(150 \mu \mathrm{l})$ was subsequently added to dissolve the formazan crystals and the absorbance was read at $570 \mathrm{~nm}$ using a microplate reader (Thermo Fisher Scientific, Inc., Waltham, MA, USA). Data were expressed as the percentage viability, assuming that the absorbance of untreated control cells was $100 \%$. The percentage cell viability was calculated using the following formula: Cell viability $(\%)=\left[\left(\mathrm{A}_{570, \text { sample }}-\mathrm{A}_{570, \text { blank }}\right) /\left(\mathrm{A}_{570, \text { control }}-\mathrm{A}_{570, \text { blank }}\right)\right] \times 100$.

Analysis of morphological alterations of cells by light microscopy. U2OS cells were treated with 0,25 or $35 \mu \mathrm{M} \mathrm{VK} 4$ for $24 \mathrm{~h}$. Shrinkage and detachment of the VK4 treated cells were observed by phase contrast microscopy (Olympus IX71 microscope; Olympus Corporation, Tokyo, Japan) (n=3).

Analysis of apoptosis by annexin V-fluorescein isothiocyanate (FITC) and propidium iodide (PI) staining. A total of $4 \times 10^{6} \mathrm{U} 2 \mathrm{OS}$ cells were treated with 0,25 or $35 \mu \mathrm{M} \mathrm{VK} 4$ in the presence or absence of the pan-caspase inhibitor carbobenzoxy-valyl-alanyl-aspartyl-(O-methyl) -fluoromethylketone (Z-VAD-FMK; $50 \mu \mathrm{M}$ ). Following treatment, cells were harvested, washed with $\mathrm{PBS}$, and resuspended in $200 \mu \mathrm{l}$ binding buffer containing $5 \mu \mathrm{l}$ annexin $\mathrm{V}$ before they were incubated in the dark for $10 \mathrm{~min}$ at room temperature, according to the manufacturer's instructions (Beyotime Institute of Biotechnology). Cells were subsequently labeled with $10 \mu \mathrm{l}$ PI and the samples were immediately analyzed by the Multicycle AV software using the Beckman Coulter Epics XL Flow Cytometer (Beckman Coulter, Inc., Brea, CA, USA).

Cell cycle analysis. Cell cycle analysis was performed as described previously (10). Briefly, 4x $10^{6}$ U2OS cells were treated with 0,25 or $35 \mu \mathrm{M} \mathrm{VK} 4$ for $24 \mathrm{~h}$. The cells were then washed with PBS and fixed with $70 \%$ ice cold ethanol at $4^{\circ} \mathrm{C}$ overnight. After washing twice with PBS, cells were stained with a PBS solution containing $50 \mu \mathrm{g} / \mathrm{ml}$ of PI and $100 \mu \mathrm{g} / \mathrm{ml}$ RNase A for $30 \mathrm{~min}$ in the dark at room temperature. The stained cells were analyzed for cell cycle phase distribution using Beckman Coulter Epics XL (Beckman Coulter, Inc.).

Flow cytometric analysis of reactive oxygen species (ROS) generation and mitochondrial membrane potential (MMP). In order to determine the level of ROS generation and the MMP, cells were stained with 2',7'-dichlorodihydrofluorescein diacetate (DCFH-DA) and rhodamine 123 (Rho-123), respectively, as described previously (9). Briefly, $4 \times 10^{6} \mathrm{U} 2 \mathrm{OS}$ cells were incubated with 0,25 or $35 \mu \mathrm{M} \mathrm{VK} 4$ for $24 \mathrm{~h}$. The cells were then harvested, washed with PBS and incubated with DCFH-DA $(10 \mu \mathrm{M})$ or Rho-123 $(5 \mu \mathrm{g} / \mathrm{ml})$ in the dark for $30 \mathrm{~min}$ at room temperature. After washing with PBS, the samples were analyzed for the fluorescence of DCF or Rho-123 by flow cytometry (Beckman Coulter Epics XL; Beckman Coulter, Inc.).

Wound healing assay. Cell mobility was assessed using an in vitro scratch wound assay. A total of $4 \times 10^{6} \mathrm{U} 2 \mathrm{OS}$ cells were seeded in 6-well plates containing complete medium until $90 \%$ confluent. The plate surface was then scraped with a sterile, $200-\mu 1$ tip and washed twice with PBS to remove remaining cell debris, before the cells were incubated in DMEM medium containing $1 \% \mathrm{FBS}$, in the presence or absence of $25 \mu \mathrm{M} \mathrm{VK} 4$ for $24 \mathrm{~h}$. The cells were then observed under an inverted light microscope (Olympus Corporation) and photographed at x100 magnification. Experiments were performed in triplicate. The distance between the wound edges was measured with a graduated ruler, and the relative scratch breadth of VK4-treated samples was presented as the ratio of the average breadth of treatment cells vs. the average breadth of control cells.

Cell migration assay. In vitro cancer cell migration activities were evaluated using Transwell microplates. For cell migration, $1 \times 10^{5}$ cells in $200 \mu \mathrm{l}$ of DMEM medium containing $1 \%$ FBS with or without $25 \mu \mathrm{M}$ VK4, were seeded in the upper Transwell insert chamber containing a polycarbonate filter (diameter, $6.5 \mathrm{~mm}$; pore size, $8 \mu \mathrm{m}$; Costar; Corning Life Sciences, NY, USA). DMEM medium $(600 \mu \mathrm{l})$ containing $10 \%$ FBS (chemoattractant) was added to the lower chamber, and the plates were incubated for $24 \mathrm{~h}$ at $37^{\circ} \mathrm{C}$ in $5 \% \mathrm{CO}_{2}$. Cells that had traversed the membrane were fixed with paraformaldehyde, stained with Coomassie Brilliant Blue R-250 dye (cat. no. 27816; Sigma-Aldrich; Merck Millipore), and were visualized and counted using an inverted light microscope. The cells that did not migrate were removed from the top of the transwell filters by scraping. Experiments were performed in triplicate. The relative migration of cells was presented as the ratio of average cell migration in the control group vs. the average cell migration in the treatment group. 
Western blot analysis. U2OS cells $\left(4 \times 10^{6}\right)$ were treated with 0,25 or $35 \mu \mathrm{M} \mathrm{VK} 4$ for $24 \mathrm{~h}$. Adherent and detached cells were collected and total protein was extracted as described previously (10). The protein concentrations were determined using the NanoDrop 1000 Spectrophotometer (NanoDrop Technologies; Thermo Fisher Scientific, Inc.). Proteins $(50 \mu \mathrm{g})$ were separated by $8-12 \%$ sodium dodecyl sulfate-polyacrylamide gel electrophoresis and transferred to a polyvinylidine difluoride membrane. After blocking with $5 \%(\mathrm{w} / \mathrm{v})$ non-fat milk for $2 \mathrm{~h}$ and washing with tris-buffered saline-Tween 20 solution (TBST), membranes were incubated with Bcl-2 (dilution, 1:1,000; cat. no. AB112), Bax (dilution, 1:300; cat. no. AB026), cleaved caspase-3 (dilution, 1:500; cat. no. AC031) and $\beta$-actin (dilution, 1:400; cat. no. sc-134542) primary antibodies overnight at $4^{\circ} \mathrm{C}$. After washing with TBST, the blots were incubated with HRP-conjugated goat anti-rabbit IgG or goat anti-mouse IgG secondary antibodies (dilution, 1:5,000; cat. no. sc-45090) for $1 \mathrm{~h}$ at room temperature. Blots were washed with TBST and signals were detected using the ECL plus chemiluminescence kit (Merck Millipore) on X-ray film.

Statistical analysis. Data are expressed as the mean \pm standard error. Differences between two groups were determined using the Student's $t$-test, while differences among $>2$ groups were determined using one-way analysis of variance followed by Tukey's multiple comparison test. $\mathrm{P}<0.05$ was considered to indicate a statistically significant difference.

\section{Results}

VK4 inhibits the growth of U2OS osteosarcoma cells. The effect of VK4 on the viability of U2OS cells was evaluated using an MTT assay. As shown in Fig. 1B, VK4 treatment significantly inhibited the growth of U2OS cells in a dose-dependent manner $(\mathrm{P}<0.05)$. The $\mathrm{IC}_{50}$ value of $\mathrm{VK} 4$ was $25 \mu \mathrm{M}$ following $24 \mathrm{~h}$ treatment. The rate of growth inhibition of U2OS cells was $>70 \%$ at $35 \mu \mathrm{M}$ when compared with untreated controls (Fig. 1B). Therefore, concentrations of 25 and $35 \mu \mathrm{M} \mathrm{VK} 4$ were selected for further mechanistic studies.

VK4 induces morphological alterations in U2OS osteosarcoma cells. To examine the effect of VK4 on U2OS cell morphology, cells were treated with increasing concentrations of VK4 for $24 \mathrm{~h}$ and cell morphology was observed under a phase contrast microscope. As shown in Fig. 1C, increasing concentrations of VK4 induced severe morphological alterations indicative of cell death, including a reduction in the total number of cells and an increase in the number of detached cells in the culture medium.

VK4 induces apoptosis and S phase cell cycle arrest in U2OS osteosarcoma cells. Apoptosis and cell cycle arrest are the two major causes of cell growth inhibition (1). The effect of VK4 on U2OS cell apoptosis was determined by annexin V-FITC/PI staining and flow cytometry analysis. As shown in Fig. 2, VK4 induced apoptosis in U2OS cells in a dose-dependent manner. In addition, pretreatment of cells with the pan-caspase inhibitor Z-VAD-FMK, significantly attenuated the apoptotic effects of VK4 $(\mathrm{P}<0.05)$. This indicates that VK4 induces apoptosis in $\mathrm{U} 2 \mathrm{OS}$ cells via caspase activation.<smiles>CC(=O)Oc1cc(C)c(OC(C)=O)c2ccccc12</smiles>

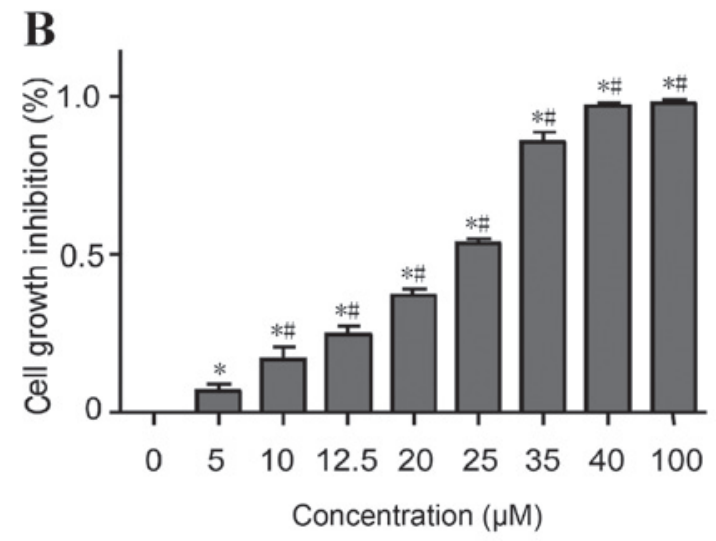

C VK4 24 h

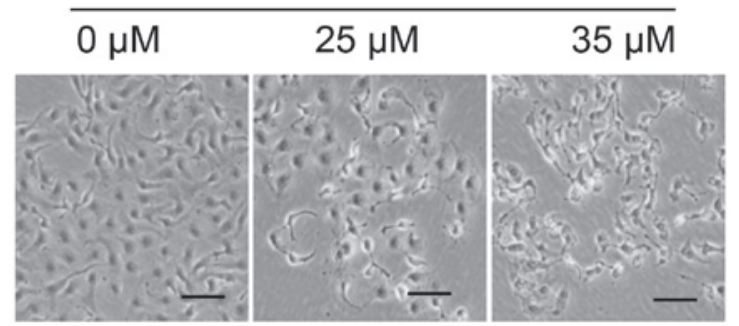

Figure 1. Chemical structure of VK4 and its effect on the viability and growth of U2OS osteosarcoma cells. (A) The chemical structure of VK4. (B) Cells were treated with DMSO or different concentrations of VK4 $(5-100 \mu \mathrm{M})$ for $24 \mathrm{~h}$, and cell viability was determined using the 3-(4,5-dimethylthiazol-2-yl)-2,5-diphenyltetrazolium bromide assay. Data are expressed as the mean \pm standard error $(n=3)$. ${ }^{*} \mathrm{P}<0.05$ vs. the untreated controls; ${ }^{\sharp} \mathrm{P}<0.05$ vs. $5 \mu \mathrm{M}$ VK4-treated controls. (C) Cells were treated with different concentrations of VK4 for $24 \mathrm{~h}$ and morphological alterations were observed by phase contrast microscopy $(\mathrm{n}=3)$. Scale bar, $20 \mu \mathrm{m}$. VK4, vitamin K4; DMSO, dimethyl sulfoxide.

Induction of cell cycle arrest was examined using PI staining and flow cytometry analysis. As shown in Fig. 3, a dose-dependent increase in the percentage of cells arrested in $\mathrm{S}$ phase was observed following treatment with VK4. Treatment with 25 and $35 \mu \mathrm{M}$ VK4 significantly increased the percentage of cells in $\mathrm{S}$ phase from $23.73 \pm 1.94$ to $38.9 \pm 1.53$ and $51.23 \pm 0.93 \%$, respectively. A corresponding decrease in the percentage of cells in G0/G1 phase from $45.48 \pm 2.43$ to $38.13 \pm 1.82$ and $28.36 \pm 2.91 \%$, and $\mathrm{G} 2 / \mathrm{M}$ phase from $28.5 \pm 1.21$ to $22.16 \pm 0.78$ and $18.26 \pm 1.69 \%$ was observed following treatment with 25 and $35 \mu \mathrm{M} \mathrm{VK} 4$, respectively $(\mathrm{P}<0.05)$.

VK4 induces ROS generation and disrupts the MMP in U2OS osteosarcoma cells. Intracellular ROS generation in U2OS cells was evaluated by flow cytometry analysis using 

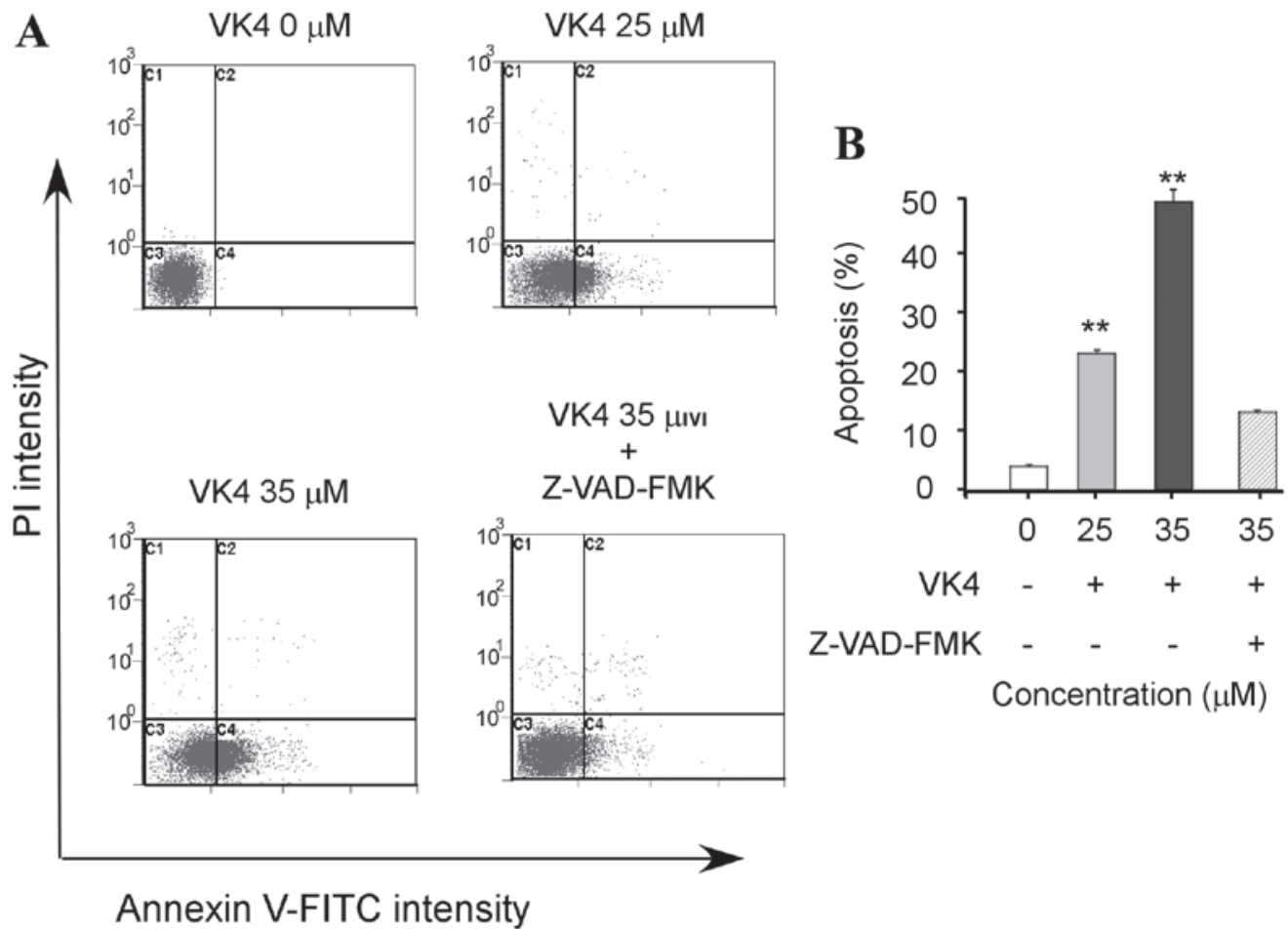

Figure 2. Flow cytometry analysis of apoptosis in U2OS osteosarcoma cells following treatment with 0,25 or $35 \mu \mathrm{M}$ VK4 in the presence or absence of $50 \mu \mathrm{M}$ Z-VAD-FMK for $24 \mathrm{~h}$. (A) After staining with annexin V/PI, cells were analyzed by flow cytometry to determine the apoptosis rate. (B) Quantitative analysis of the percentage of apoptotic cells in each treatment group. Data are expressed as mean \pm standard error $(\mathrm{n}=3) .{ }^{* *} \mathrm{P}<0.01$ vs. untreated controls. VK4, vitamin K4; Z-VAD-FMK, carbobenzoxy-valyl-alanyl-aspartyl-(O-methyl)-fluoromethylketone; PI, propidium iodide; FITC, fluorescein isithiocyanate.

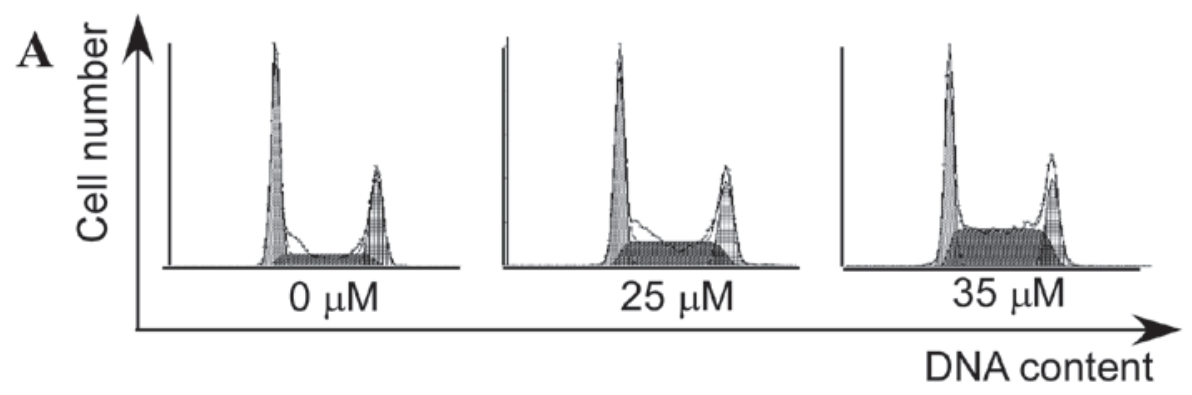

B

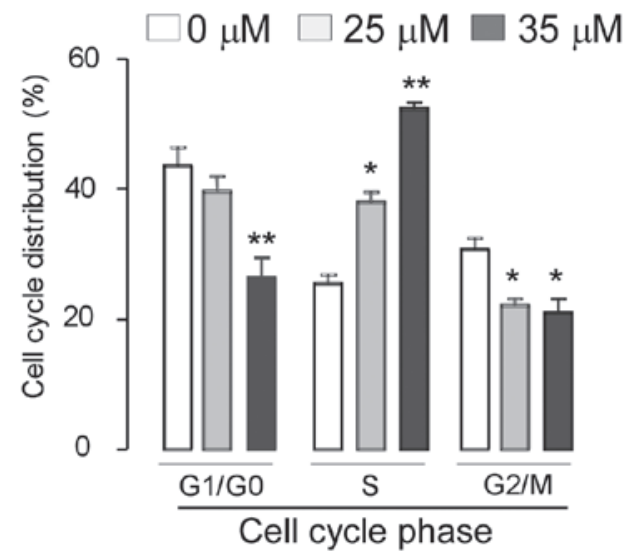

Figure 3. Flow cytometry analysis of the cell cycle profile of U2OS osteosarcoma cells. (A) Flow cytometry plots showing the cell cycle phase distribution of U2OS cells following treatment with 0,25 or $35 \mu \mathrm{M}$ VK4 for $24 \mathrm{~h}$. Cells were stained with $50 \mu \mathrm{g} / \mathrm{ml} \mathrm{PI}$ and $100 \mu \mathrm{g} / \mathrm{ml}$ RNase A. (B) Quantitative analysis of the percentage of cells in G1/G0, S and G2/M phases. Data are presented as the mean \pm standard error $(\mathrm{n}=3)$. ${ }^{*} \mathrm{P}<0.05$ and ${ }^{* * *} \mathrm{P}<0.01$ vs. untreated controls. VK4, vitamin K4; PI, propidium iodide.

DCFH-DA. As shown in Fig. 4, the level of ROS in U2OS cells treated with 25 and $35 \mu \mathrm{M}$ VK4 was significantly increased when compared with untreated controls $(82.6 \pm 1.2$ and $95.1 \pm 1.8$ vs. $71.2 \pm 0.9 \%$ respectively; $\mathrm{P}<0.05$ ). 

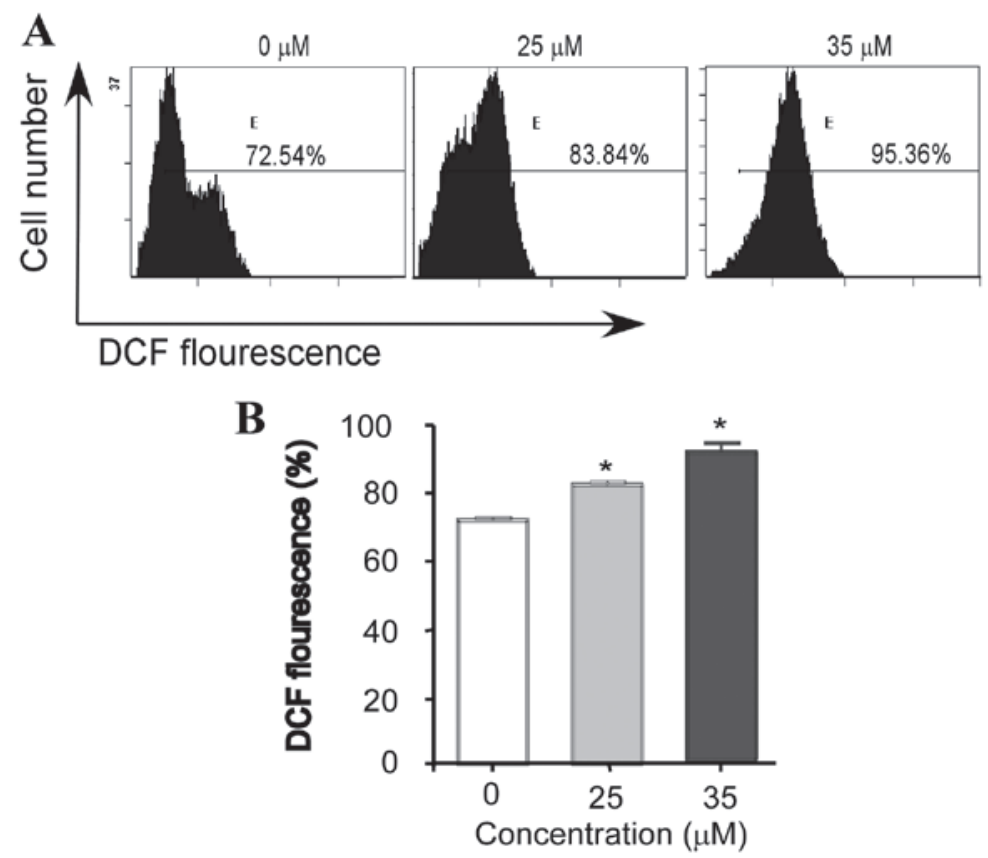

Figure 4. Flow cytometry analysis of ROS generation in U2OS cells treated with VK4. (A) Cells were treated with 0,25 or $35 \mu \mathrm{M}$ VK4 for $24 \mathrm{~h}$ and ROS generation was determined by staining the cells with DCFH-DA. (B) Quantitative analysis of DCF fluorescence intensity in each treatment group. Data are presented as the mean \pm standard error $(n=3)$. "P<0.05 vs. untreated controls. ROS, reactive oxygen species; VK4, vitamin K4; DCFH-DA, 2', 7'-dichlorodihydrofluorescein diacetate.
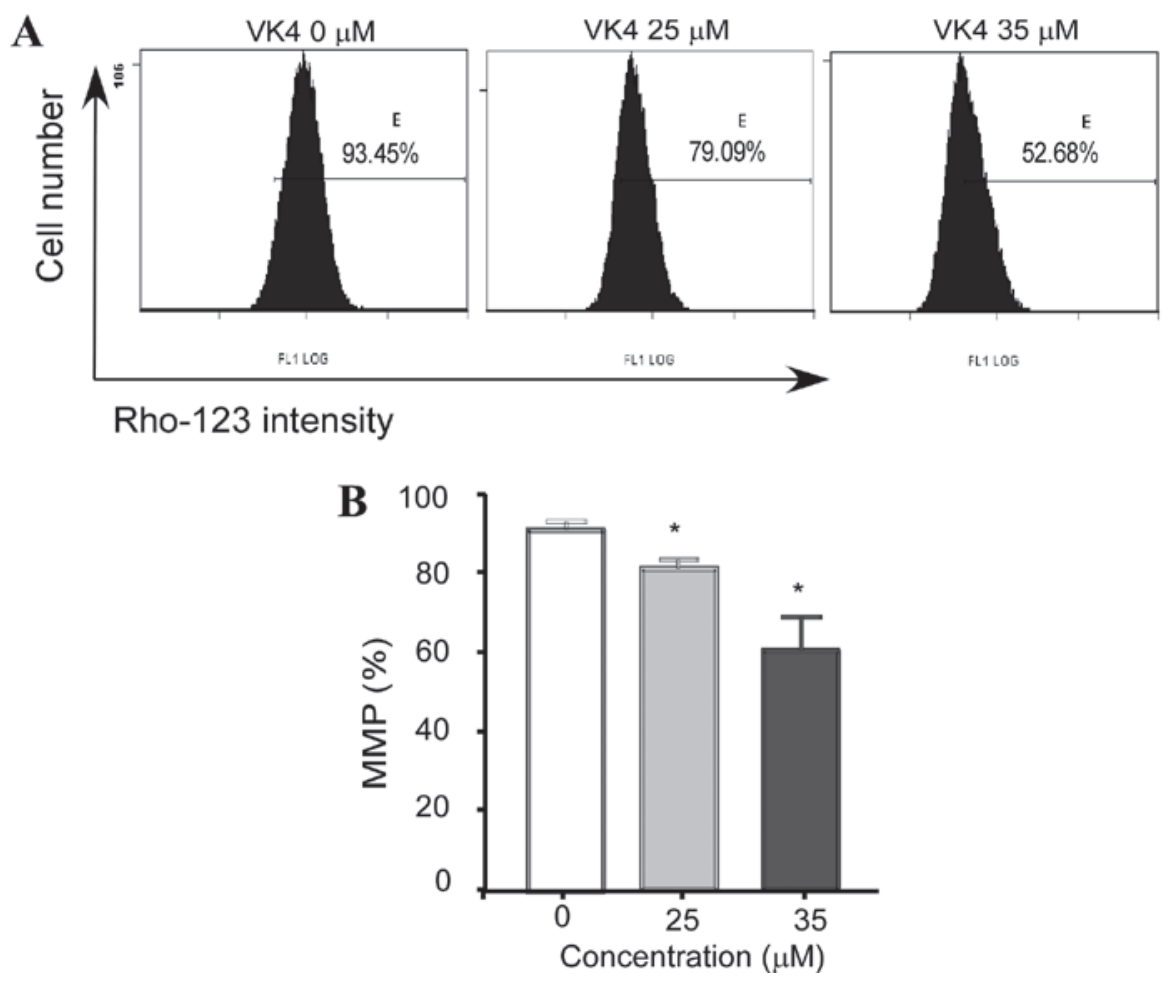

Figure 5. Flow cytometry analysis of MMP in U2OS cells following treatment with VK4. (A) Cells were treated with 0,25 or $35 \mu \mathrm{M}$ VK4 for $24 \mathrm{~h}$ and MMP was determined by staining the cells with Rho-123. (B) Quantitative analysis of the percentage change in MMP in all treatment groups. Data are presented as the mean \pm standard error $(n=3)$. ${ }^{*} \mathrm{P}<0.05$ vs. untreated controls. MMP, mitochondrial membrane potential; VK4, vitamin K4; Rho-123, rhodamine-123.

Depolarization of the MMP is a characteristic feature of apoptosis (1). Excessive intracellular ROS production has been demonstrated to induce apoptosis by disrupting the MMP(15).In order to investigate the role of ROS in VK4-mediated apoptosis, the MMP in U2OS cells was examined using Rho-123 and flow cytometry analysis. As shown in Fig. 5, a significant reduction in MMP was observed in cells following treatment with 25 and $35 \mu \mathrm{M}$ VK4 when compared with untreated controls 

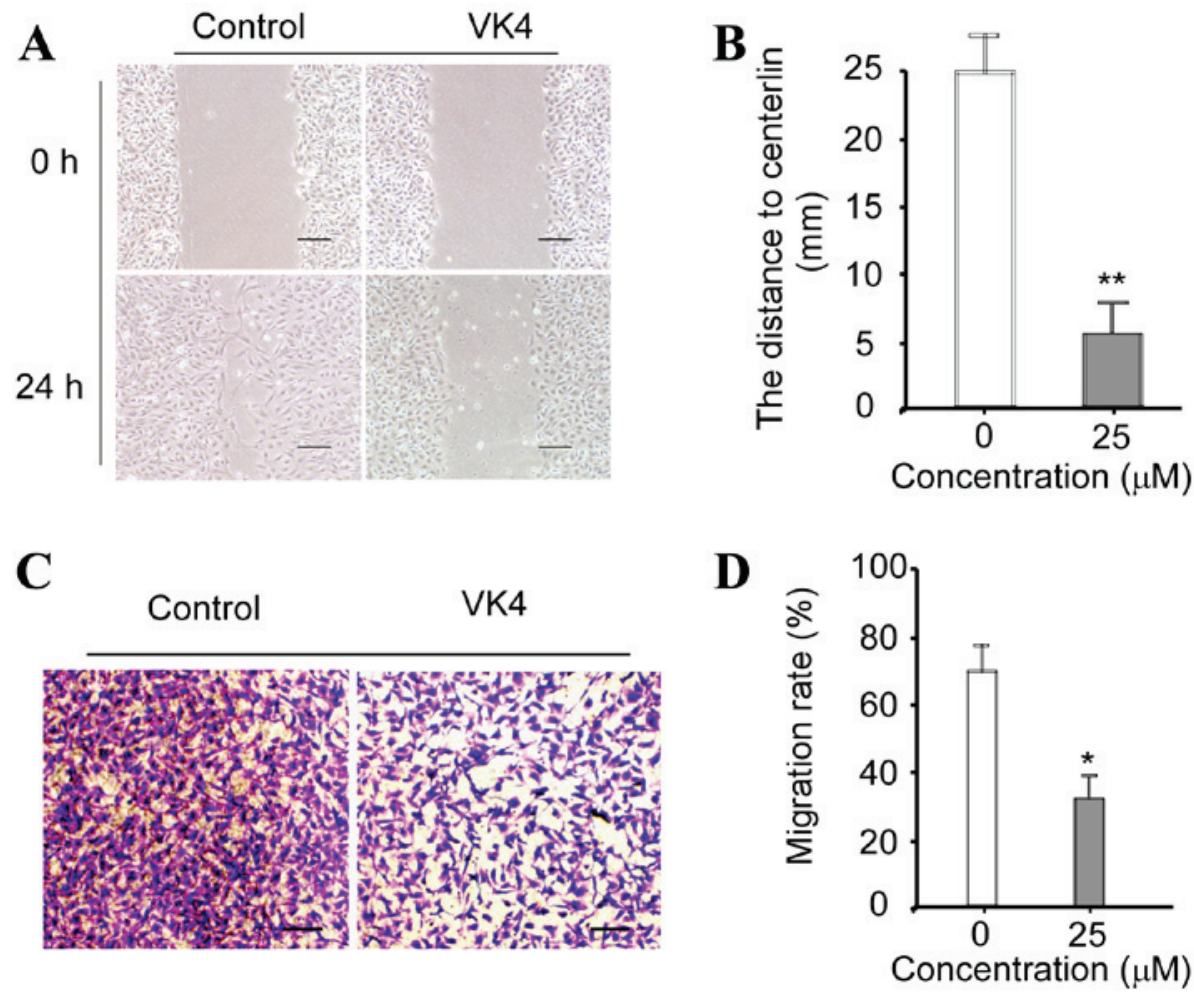

Figure 6. Effect of VK4 on U2OS cell migration. (A) Representative microscope images of an in vitro wound assay demonstrating the effect of 0 or $25 \mu \mathrm{M}$ VK4 on U2OS cell migration. Scale bar, $20 \mu \mathrm{m}$. (B) Quantitative analysis of wound closure in both treatment groups. A significant reduction in wound closure was observed in cells treated with VK4 compared to untreated controls. (C) Representative microscope images demonstrating the effect of VK4 on U2OS cell migration in vitro as determined using a Transwell migration assay. Cells were stained with Coomassie Brilliant Blue R-250 dye. Scale bar, $20 \mu \mathrm{m}$. (D) Quantitative analysis of the migration rate of cells in both treatment groups. VK4 treatment significantly suppressed the migration rate of cells when compared to untreated controls. Data are presented as the mean \pm standard error $(n=3)$. ${ }^{*} \mathrm{P}<0.05$ and ${ }^{* *} \mathrm{P}<0.01$ vs. untreated controls. VK4, vitamin $\mathrm{K} 4$.

$\mathbf{A}$

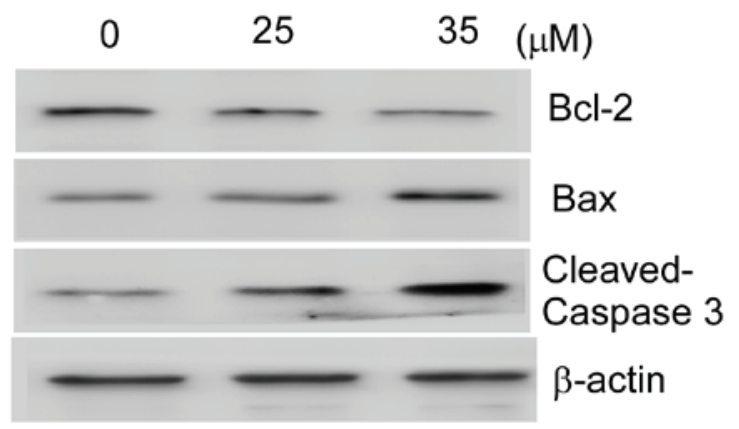

B

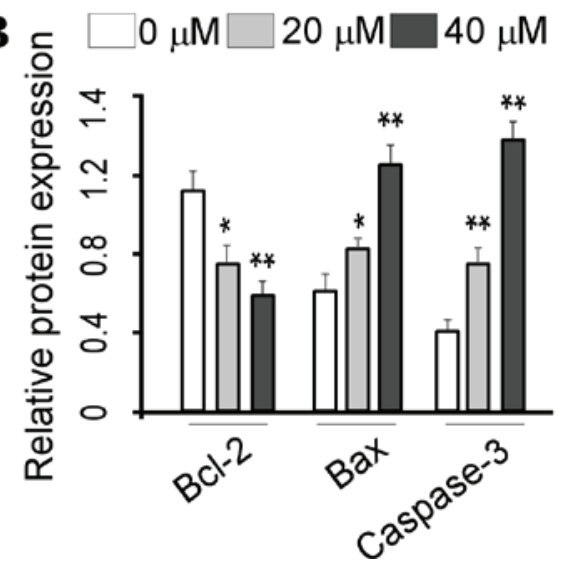

Figure 7. Effect of VK4 on the expression of apoptosis regulators. (A) Western blot analysis of Bcl-2, Bax and cleaved caspase-3 in U2OS cells treated with 0 , 25 or $35 \mu \mathrm{M}$ VK4 for $24 \mathrm{~h}$. The protein expression of $\beta$-actin was used as loading control. (B) Quantification of band densities in each treatment group. Data are presented as the mean \pm standard error $(\mathrm{n}=3)$. ${ }^{*} \mathrm{P}<0.05$ and ${ }^{* *} \mathrm{P}<0.01$ vs. untreated controls. VK4, vitamin $\mathrm{K} 4$.

$(79.3 \pm 1.75 \%$ and $53.40 \pm 2.9 \%$ vs. $93.03 \pm 1.35 \%$, respectively; $\mathrm{P}<0.05)$.

VK4 suppresses the migration of U2OS cells in vitro. The effect of VK4 on the migration of U2OS cells in vitro was determined using wound healing and Transwell migration assays, respectively. As shown in Fig. 6A and B, the distance to the center of the 'wound' was significantly reduced in cells incubated with $25 \mu \mathrm{M} \mathrm{VK} 4$ for $24 \mathrm{~h}$ when compared with untreated controls. As shown in Fig. 6C and D, the migration rate of cells was significantly reduced following treatment with $25 \mu \mathrm{M}$ VK4 when compared with untreated controls $(\mathrm{P}<0.05)$. Taken together, these data indicate that VK4 inhibits the migration of $\mathrm{U} 2 \mathrm{OS}$ cells in vitro.

VK4 induces apoptosis in U2OScells through the mitochondrial pathway. ROS generation and mitochondrial membrane dissipation are characteristic features of mitochondrial 
apoptosis (11). Therefore, in order to investigate the molecular mechanisms underlying the pro-apoptotic effects of VK4 on U2OS cells, the protein expression levels of Bcl-2, Bax and caspase-3 were examined. As shown in Fig. 7, VK4 significantly increased the protein expression of pro-apoptotic protein Bax, and significantly decreased the expression of anti-apoptotic protein $\mathrm{Bcl}-2$ in a dose-dependent manner when compared with untreated controls $(\mathrm{P}<0.05)$. Cleavage of caspase-3 is a major hallmark of apoptosis (1). Therefore, the protein expression of cleaved caspase-3 in VK4-treated U2OS cells was examined. As shown in Fig. 7, VK4 treatment significantly increased the expression of cleaved caspase-3 in a dose-dependent manner, when compared with untreated controls $(\mathrm{P}<0.05)$. Taken together, these results indicate that VK4 may induce the intrinsic apoptosis pathway in U2OS cells.

\section{Discussion}

VK4 is a synthetic hydrophilic menadione compound, which is used clinically as a treatment for hemostasis (14). Jiang et al (14) demonstrated that VK4 induced cytotoxic effects in human prostate carcinoma PC-3 cells. However, the molecular mechanisms underlying VK4-induced cytotoxicity in PC-3 cells remain largely unknown. Therefore, the aim of the present study was to determine whether VK4 inhibits the growth of U2OS osteosarcoma cells in vitro. Consistent with Jian et al (14), VK4 was observed to inhibit the growth of $\mathrm{U} 2 \mathrm{OS}$ cells in a dose-dependent manner.

Apoptosis and cell cycle arrest are the two major causes of cell growth inhibition in cancer cells $(16,17)$. A number of studies indicate that the majority of chemotherapeutic drugs inhibit tumor cell growth via induction of apoptosis (18-20). In the present study, VK4 arrested the cell cycle of U2OS osteosarcoma cells at $\mathrm{S}$ phase and induced apoptosis in cells in a dose-dependent manner. Apoptosis, a form of programmed cell death, is a highly controlled and evolutionarily conserved process characterized by cell shrinkage, membrane blebbing, loss of plasma membrane integrity, DNA fragmentation and cleavage of caspase-3 $(21,22)$. Consistent with these features of apoptosis, VK4-treated U2OS cells exhibited cell shrinkage and cleavage of caspase-3. Apoptosis can be divided into the following three major categories: i) Mitochondrial caspase-dependent apoptosis or intrinsic apoptosis; ii) extrinsic apoptosis; and iii) caspase-independent apoptosis $(23,24)$. In order to gain further insight into the molecular mechanisms underlying VK4-induced apoptosis, annexin V/PI staining of VK4-treated U2OS cells exposed to a pan-caspase inhibitor Z-VAD-FMK was performed. Treatment of cells with Z-VAD-FMK significantly inhibited the apoptotic effects of VK4, which suggests that VK4 may induce caspase-dependent apoptosis in U2OS cells.

It is well established that the mitochondria serve key roles in the regulation of cell death and proliferation through the production of $\operatorname{ROS}(14,25)$. Mitochondrial apoptosis is associated with ROS production and MMP dissipation (26). In the present study, VK4 increased ROS generation and decreased the MMP in U2OS cells in a dose-dependent manner.

ROS may lead to extensive oxidative damage, including mitochondrial damage, lipid peroxidation and DNA damage.
In addition, ROS are known to function as second messengers to activate diverse redox-sensitive signaling cascades, such as the mitochondrial intrinsic apoptotic cascade, through interaction with Bcl-2 family proteins (1). The Bcl-2 protein family includes a wide variety of antiapoptotic proteins, such as Bcl-2, and pro-apoptotic proteins, such as Bax, which are key factors involved in mediating the permeabilization of the mitochondrial outer membrane and regulating apoptosis $(27,28)$. Under normal conditions, Bax is present in the cytosol, and is negatively regulated by the antiapoptotic protein $\mathrm{Bcl}-2$. Thus, $\mathrm{Bcl}-2 / \mathrm{Bax}$ is considered to be a molecular regulator that controls cell fate. In the presence of a pro-apoptotic stimulus, the Bcl-2/Bax ratio decreases and the cell undergoes apoptosis. ROS have been demonstrated to inhibit the anti-apoptotic protein $\mathrm{Bcl}-2$ and activate the pro-apoptotic protein Bax (29-31). In the present study, VK4 treatment increased the level of ROS and dissipated the MMP in U2OS cells. Therefore, the protein expression levels of Bcl-2 and Bax were examined. VK4 treatment significantly increased the expression of Bax and significantly decreased the expression of Bcl-2. These results suggest that VK4 induces the intrinsic apoptotic cell death signaling pathway in U2OS osteosarcoma cells. Consistent with these observations, Jiang et al (14) demonstrated a similar effect of VK4 on Bcl-2 family protein expression modulation.

Osteosarcoma is characterized by resistance to chemotherapy and the development of metastases. Although the use of multi-agent chemotherapy in combination with surgery has improved the five-year patient survival rate to $60-70 \%(1,32)$, the five-year survival rate of patients with osteosarcoma that have developed metastases is only $20 \%$. In addition, current therapeutic strategies are not effective for the treatment of these patients (33). Therefore, the identification of agents that not only inhibit the growth of tumor cells, but also suppress the metastatic activity of cancer cells, is highly desirable. In the present study, the effect of VK4 on U2OS cell migration was investigated using wound healing and Transwell migration assays. The results demonstrated that VK4 effectively inhibited the migration of $\mathrm{U} 2 \mathrm{OS}$ cells in vitro. However, a detailed mechanistic study is required to determine the precise mechanisms underlying the anti-metastatic activity of VK4 in these cells.

In conclusion, the results of the present study demonstrated that VK4 inhibits the growth and induces apoptosis of U2OS osteosarcoma cells. To the best of our knowledge, this is the first study that has provided evidence demonstrating the inhibitory effects of VK4 on U2OS cell growth. Apoptosis was associated with ROS generation, MMP dissipation, modulation of Bcl-2 family protein expression and activation of caspase-3. In addition, VK4 suppressed the migration of U2OS cells in vitro. These results suggest that VK4 may present a potential compound in the development of future therapies for the treatment of osteosarcoma. Further investigation is required to confirm the contribution of VK4 as an anti-tumor therapy using in vivo studies.

\section{Acknowledgements}

The present study was supported by Binzhou Medical University Affiliated Hospital scientific research funds and Binzhou Medical University (grant no. BY2015KYQD27). 


\section{References}

1. Di W, Khan M, Rasul A, Sun M, Sui Y, Zhong L, Yang L, Zhu Q, Feng L and Ma T: Isoalantolactone inhibits constitutive $\mathrm{NF}-\kappa \mathrm{B}$ activation and induces reactive oxygen species-mediated apoptosis in osteosarcoma U2OS cells through mitochondrial dysfunction. Oncol Rep 32: 1585-1593, 2014.

2. Sun L, Li Y, Li H, Zhang J, Li B and Ye Z: Analysis of chemotherapy dosage and dosage intensity and survival outcomes of high-grade osteosarcoma patients younger than 40 years. Clin Ther 36: 567-578, 2014.

3. Zhang J, Zhu X, Li H, Li B, Sun L, Xie T, Zhu T, Zhou H and Ye Z: Piperine inhibits proliferation of human osteosarcoma cells via $\mathrm{G} 2 / \mathrm{M}$ phase arrest and metastasis by suppressing MMP-2/-9 expression. Int Immunopharmacol 24: 50-58, 2015.

4. Lee JS, DuBois SG, Boscardin WJ, Wustrack RL and Goldsby RE: Secondary malignant neoplasms among children, adolescents, and young adults with osteosarcoma. Cancer 120: 3987-3993, 2014.

5. Yao C, Wei JJ, Wang ZY, Ding HM, Li D, Yan SC, Yang YJ and Gu ZP: Perifosine induces cell apoptosis in human osteosarcoma cells: New implication for osteosarcoma therapy? Cell Biochem Biophys 65: 217-227, 2013.

6. Li YS, Deng ZH, Zeng C and Lei GH: Role of osteopontin in osteosarcoma. Med Oncol 32: 449, 2015.

7. Wei G, Wang M and Carr BI: Sorafenib combined vitamin K induces apoptosis in human pancreatic cancer cell lines through RAF/MEK/ERK and c-Jun NH2-terminal kinase pathways. J Cell Physiol 224: 112-119, 2010.

8. Mamede AC, Tavares SD, Abrantes AM, Trindade J, Maia JM and Botelho MF: The role of vitamins in cancer: A review. Nutr Cancer 63: 479-494, 2011.

9. Baran I, Ganea C, Scordino A, Musumeci F, Barresi V, Tudisco S, Privitera S, Grasso R, Condorelli DF, Ursu I, et al: Effects of menadione, hydrogen peroxide, and quercetin on apoptosis and delayed luminescence of human leukemia Jurkat T-cells. Cell Biochem Biophys 58: 169-179, 2010.

10. Li L, Qi Z, Qian J, Bi F, Lv J, Xu L, Zhang L, Chen H and Jia R Induction of apoptosis in hepatocellular carcinoma Smmc-7721 cells by vitamin $\mathrm{K}(2)$ is associated with $\mathrm{p} 53$ and independent of the intrinsic apoptotic pathway. Mol Cell Biochem 342: 125-131, 2010.

11. Oshiro Y, Takada Y, Enomoto T, Fukao K, Ishikawa S and Iijima T: A resected case of metachronous liver metastasis from lung cancer producing alpha-fetoprotein (AFP) and protein induced by vitamin $\mathrm{K}$ absence or antagonist II (PIVKA-II). Hepatogastroenterology 1: 1144-1147, 2004.

12. Akiyoshi T, Matzno S, Sakai M, Okamura N and Matsuyama K: The potential of vitamin $\mathrm{K} 3$ as an anticancer agent against breast cancer that acts via the mitochondria-related apoptotic pathway. Cancer Chemother Pharmacol 65: 143-150, 2009.

13. Duan F, Yu Y, Guan R, Xu Z, Liang H and Hong L: Vitamin K2 induces mitochondria-related apoptosis in human bladder cancer cells via ROS and JNK/p38 MAPK signal pathways. PLoS One 11: e0161886, 2016.

14. Jiang Y, Yang J, Yang C, Meng F, Zhou Y, Yu B, Khan M and Yang H: Vitamin K4 induces tumor cytotoxicity in human prostate carcinoma PC-3 cells via the mitochondria-related apoptotic pathway. Pharmazie 68: 442-448, 2013.

15. Vermeer C: Vitamin K: The effect on health beyond coagulation-an overview. Food Nutr Res 56, 2012.

16. Chan KT, Meng FY, Li Q, Ho CY, Lam TS, To Y, Lee WH, $\mathrm{Li} \mathrm{M}$, Chu KH and Toh M: Cucurbitacin B induces apoptosis and S phase cell cycle arrest in BEL-7402 human hepatocellular carcinoma cells and is effective via oral administration. Cancer Lett 294: 118-124, 2010.

17. Khan M, Zheng B, Yi F, Rasul A, Gu Z, Li T, Gao H, Qazi JI, Yang $\mathrm{H}$ and Ma T: Pseudolaric acid B induces caspase-dependent and caspase-independent apoptosis in u87 glioblastoma cells. Evid Based Complement Alternat Med 2012: 957568, 2012.
18. Rasul A, Di J, Millimouno FM, Malhi M, Tsuji I, Ali M, Li J and Li X: Reactive oxygen species mediate isoalantolactone-induced apoptosis in human prostate cancer cells. Molecules 18: 9382-9396, 2013.

19. Min Z, Wang L, Jin J, Wang X, Zhu B, Chen H and Cheng Y: Pyrroloquinoline quinone induces cancer cell apoptosis via mitochondrial-dependent pathway and down-regulating cellular Bcl-2 protein expression. J Cancer 5: 609-624, 2014.

20. Zhao X, Liu X and Su L: Parthenolide induces apoptosis via TNFRSF10B and PMAIP1 pathways in human lung cancer cells. J Exp Clin Cancer Res 33: 3, 2014.

21. Wu H, Che X, Zheng Q, Wu A, Pan K, Shao A, Wu Q, Zhang J and Hong Y: Caspases: A molecular switch node in the crosstalk between autophagy and apoptosis. Int J Biol Sci 10: 1072-1083, 2014.

22. Wu HJ, Pu JL, Krafft PR, Zhang JM and Chen S: The molecular mechanisms between autophagy and apoptosis: Potential role in central nervous system disorders. Cell Mol Neurobiol 35: 85-99, 2015.

23. Zhou X, Zhang J, Jia Q, Ren Y, Wang Y, Shi L, Liu N, Wang G, $\mathrm{Pu}$ P, You Y and Kang C: Reduction of miR-21 induces glioma cell apoptosis via activating caspase 9 and 3. Oncol Rep 24: 195-201, 2010.

24. Huang C, Chen X, Guo B, Huang W, Shen T, Sun X, Xiao P and Zhou Q: Induction of apoptosis by Icariside II through extrinsic and intrinsic signaling pathways in human breast cancer MCF7 cells. Biosci Biotechnol Biochem 76: 1322-1328, 2012.

25. Antico Arciuch VG, Elguero ME, Poderoso JJ and Carreras MC: Mitochondrial regulation of cell cycle and proliferation. Antioxid Redox Signal 16: 1150-1180, 2012.

26. Zhang R, Lee IK, Piao MJ, Kim KC, Kim AD, Kim HS, Chae S, Kim HS and Hyun JW: Butin (7,3',4'-trihydroxydihydroflavone) reduces oxidative stress-induced cell death via inhibition of the mitochondria-dependent apoptotic pathway. Int J Mol Sci 12: 3871-3887, 2011.

27. Kaparou M, Choumerianou D, Perdikogianni C, Martimianaki G, Kalmanti M and Stiakaki E: Enhanced levels of the apoptotic BAX/BCL-2 ratio in children with acute lymphoblastic leukemia and high-risk features. Genet Mol Biol 36: 7-11, 2013.

28. Renault TT, Floros KV, Elkholi R, Corrigan KA, Kushnareva Y, Wieder SY, Lindtner C, Serasinghe MN, Asciolla JJ, Buettner C, et al: Mitochondrial shape governs BAX-induced membrane permeabilization and apoptosis. Mol Cell 57: 69-82, 2015.

29. Khan M, Yu B, Rasul A, Al Shawi A, Yi F, Yang H and Ma T: Jaceosidin Induces Apoptosis in U87 Glioblastoma Cells through G2/M Phase Arrest. Evid Based Complement Alternat Med 2012: 703034, 2012.

30. Khan M, Yi F, Rasul A, Li T, Wang N, Gao H, Gao R and Ma T: Alantolactone induces apoptosis in glioblastoma cells via GSH depletion, ROS generation, and mitochondrial dysfunction. IUBMB Life 64: 783-794, 2012.

31. Khan M, Li T, Ahmad Khan MK, Rasul A, Nawaz F, Sun M, Zheng Y and Ma T: Alantolactone induces apoptosis in HepG2 cells through GSH depletion, inhibition of STAT3 activation, and mitochondrial dysfunction. Biomed Res Int 2013: 719858, 2013.

32. Buddingh EP, Schilham MW, Ruslan SE, Berghuis D, Szuhai K, Suurmond J, Taminiau AH, Gelderblom H, Egeler RM, Serra M, et al: Chemotherapy-resistant osteosarcoma is highly susceptible to IL-15-activated allogeneic and autologous NK cells. Cancer Immunol Immunother 60: $575-586,2011$

33. Sakamoto A and Iwamoto Y: Current status and perspectives regarding the treatment of osteo-sarcoma: Chemotherapy. Rev Recent Clin Trials 3: 228-231, 2008. 